\title{
Amino Acid as Capping Agent for Electrolytic Synthesis of Copper Nanoparticles
}

\author{
Narayanan Selvapalam, Ramesh Prakash, M. Sivasubramanian, Karuppasamy \\ Karpagalakshmi, Lakshminarayanan Piramuthu
}

\begin{abstract}
Copper nanoparticles are the excellent resources for several applications, that include future nano-based circuits, wound healing materials and many more. Here, we have explored the synthesis of copper nanoparticles by electrolytic method of reduction using amino acids as capping agent. Unlike the other methods of nanoparticles, electrolytic synthesis is a non-toxic way of preparation and our amino acid capped copper nanoparticles were analyzed by SEM and XRD
\end{abstract}

Keywords: Electrolytic method, Copper nanoparticles, Amino acids, capping agent.

\section{INTRODUCTION}

$\mathrm{C}$ opper or gold nanoparticles provide an opportunity to link biomolecules that have contributed in many areas of applications that include drug-delivery, gene transfer, biosensors for tissue analysis or disease analysis. [1], [2] Copper/gold nanoparticles have been capped with many interesting substances such as proteins, amino acids, drugs, dyes, enzymes and many other sources to provide stable bio-functionalized nanoparticles for the biocompatibility and easy invasion into the cells and tissues [3], [4]. For the tissue engineering and wound healing copper nanoparticles are the cheap resources and furthermore, they possess good optical, electrical, catalytic, and antifungal activity. Besides, copper has been produced as nano sized wire, particles, crystals and spherical nanoparticles [5]. Copper has been exploited in applications of electronics [6], chemical sensors [7], [8], anti bacterial and antifungal research activities [9], [10]. Among the various methods of making nanoparticles from the source of copper salts, chemical reduction method gained much attention, due to the easy preparation method [11], [12], Electrolytic reduction also considered important, because it

Revised Manuscript Received on December 15, 2019.

* Correspondence Author

Narayanan Selvapalam* Center for Supramolecular Chemistry, IRC and Department of Chemistry, Kalasalingam Academy of Research and Education, Krishnankoil 626126, India. n.selvapalam@klu.ac.in

Ramesh Prakash Center for Supramolecular Chemistry, IRC and Department of Chemistry, Kalasalingam Academy of Research and Education, Krishnankoil 626126, India.n.selvapalam@klu.ac.in

M. Sivasubramanian Department of Automobile Engineering, Kalasalingam Academy of Research and Education, Krishnankoil 626126, India.m.sivasubramanian@klu.ac.in

Karuppasamy Karpagalakshmi, Department of Automobile Engineering, Kalasalingam Academy of Research and Education, Krishnankoil 626126, India.

Lakshminarayanan Piramuthu, Department of Automobile Engineering, Kalasalingam Academy of Research and Education, Krishnankoil 626126, India. does not require any reducing agents such as $\mathrm{NaBH}_{4}$, hydrazine hydrate, ascorbic acid and others. Electrolytic reduction of metal ions tends to produce very unique shapes and dimensions and for that reason, this method gained much attention recent years. However, capping agents such as amino acids, dyes, proteins or the other capping agents play much important role in defining the shapes and dimensions of nanoparticles [13], [14].

We were interested in amino acids as the capping agent, since they have bifunctionality, which may greatly affect the size and shape of the nanoparticles. Besides, the substituent of the amino acids may also contribute the morphology of the nanoparticles. Among the 20 bio-active amino acids, we were interested on glutamic acid and alanine amino acids, since these amino acids are part of Neem leaves [15]. Another good reason to select alanine is that it is an important part of human muscle. Furthermore, alanine can help to create lymphocytes and it can reduce the prostate enlargement, when used with glycine. Structurally alanine is a part vitamin B5, which support our adrenal glands. Similarly, we have selected glutamic acid for our studies, because glutamic acid has been used for the treatment of epilepsy and muscular dystrophy [16]. Besides, glutamic acid has been consumed to prevent nerve damage while taking the chemotherapy of cancer. Recently, Reetz et. al. have prepared size selective nanoparticles for the transition metals using tetraalkylammonium salts as capping agent [17]. Similarly, Gold nanorods have been obtained by electrochemical method when surfactant has been used as capping agent [18]. Recently, Wei-Shi Li et. al. have prepared amino acids copper nanoparticles using hydrazine as reducing agent; in which they obtained a variety of nano-wire and nanoparticles [19]. With these facts, we expected that the copper nanoparticles with glutamic acid or alanine as capping agent may be useful for the pharmaceutical applications. In addition, copper also displayed good antibacterial property and thus we expected that the alanine or glutamic acid capped nanoparticles can be useful in wound healing and other external applications. Alanine and glutamic acid are structurally much different in terms of substitution ( $\mathrm{R})$ groups. The $\mathrm{R}$ group of alanine is methyl, while $\mathrm{R}$ group is propionic acid for glutamic acid and that structural variation has been reflected in the shape formation and size variation of the copper nanoparticles with that amino acid as capping agent. Alanine is having the hydrophobic methyl group and glutamic acid is having hydrophilic carboxylic group at the terminal of the $\mathrm{R}$ group. That makes the major difference, while forming the nanoparticles. 
We have obtained the small sized nanoparticles for the alanine and large sized nanoparticles for glutamic acid, which essentially due the presence of different $\mathrm{R}$ groups of the amino acids functioned as capping agent. Therefore, here we have presented the synthesis of copper nanoparticles using alanine and glutamic acid as capping agent. We have characterized these nanoparticles using SEM and XRD. Applications such as chemical sensors and antibacterial studies are under investigation for these nanoparticles.

\section{EXPERIMENTAL}

\section{Preparation of glutamic acid capped copper nanoparticles}

Copper sulfate $(5 \mathrm{~g})$ and $1 \mathrm{~g} \mathrm{~mL}$ of glutamic acid were dissolved thoroughly in $100 \mathrm{~mL}$ water. Anode copper plates were having the thickness of $3 \mathrm{~mm}$ and cathode was copper rods of having the thickness of $0.5 \mathrm{~cm}$. The copper nanoparticles were deposited in the rod and the force of stirrer allowed them to settle down during the reaction. DC supply of $24 \mathrm{~V}$ and 5 A current was passed to this solution with the copper electrodes as anode as well as cathode for $3 \mathrm{~h}$ duration with stirring. The product appeared brownish mass and it was filtered and washed with water and acetone to get in powder form.

\section{Preparation of alanine capped copper nanoparticles}

Copper sulfate $(5 \mathrm{~g})$ and $1 \mathrm{~g} \mathrm{~mL}$ of alanine were dissolved thoroughly in $100 \mathrm{~mL}$ water and DC supply of $24 \mathrm{~V}$ and $5 \mathrm{~A}$ current was passed to this solution with the copper electrodes as anode as well as cathode for $3 \mathrm{~h}$ duration with stirring. The product appeared brownish and it was filtered and washed with water and acetone to get in powder form.

\section{RESULTS AND DISCUSSION}

Electrolytic synthesis of nanoparticles is the topic interest to many research groups and there are many advantages to this method, because no additional chemicals are required for the reduction and the method can be performed without having any special setup. For that reason, we have been attracted to synthesize the nanoparticles using electrolytic synthesizer [20]. Anode and cathode materials are copper rods and plates. Copper electrodes have been cleaned by emery sheet and washed with DI water and acetone before use it in the reaction chamber. Except the metal salts, no other salts have been added to avoid the electrolysis of water. We used copper sulfate pentahydrate as copper sources, because it is the inexpensive copper salts. Several of the works, similar as we envisaged metal nanoparticles (transition metals) with tetraalkylammonium salts as capping agents and gold nanorods with surfactant as capping agent have been reported. However, copper nano wire has been synthesized chemical reduction method using amino acids as capping agent and that intrigued us to examine the amino acids capped copper nanoparticles by electrolytic method. To the best of our knowledge, this is the first electrolytic synthesis report for the amino acids capped copper nanoparticles.

For that purpose, we decided to use glutamic acid (an amino acid), which contains, two carboxylic acid functional groups with one amine group and anticipated some interesting shaped molecules. Interestingly, no nanowire formation had occurred when we used glutamic acid as amino acid. It only produced the partially spherical nano-particles (Fig. 1). We used glutamic acid (1g) with copper sulfate $(5 \mathrm{~g})$ in $100 \mathrm{~mL}$ water and copper nanoparticles could have formed the complexes with the amino acids and at later stage, copper nanoparticles could have formed with amino acids as a capping agent. As shown in the fig.1, it formed a dentrimeric of nanoparticles and it appears like the grape fruits attached to the branch of the tree with variable size distribution in the range of $700 \mathrm{~nm}$ and above and some of particles appears larger in size, which may be due to the merged particles of two or more. These results could be comparable to the chemical reduction method of amino acids capped copper nanoparticles

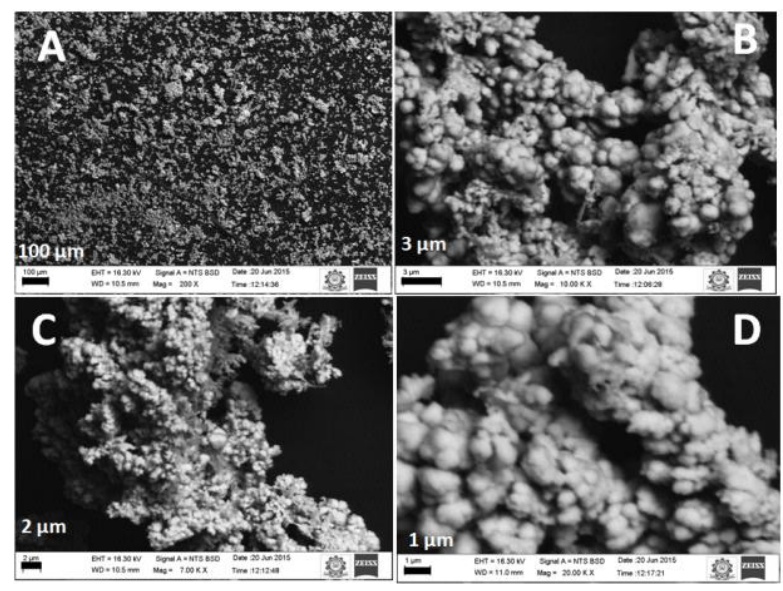

Fig. 1. SEM images of copper with glutamic acid as capping agent

prepared by Wei-Shi Li et.al. as they used $\mathrm{Cu}\left(\mathrm{NO}_{3}\right)_{2}$ as the source of copper with 20 different amino acids and reduced the copper with hydrazine at $80{ }^{\circ} \mathrm{C}$ [19]. The copper nanoparticles that was prepared by glutamic acid as capping agent was given by them and the particle sizes are very similar to that of our method of preparation indicating that the amino acids having different substitutents will be determining factor about the shapes and morphology of the nanoparticles in copper nanostructures that was prepared from different amino

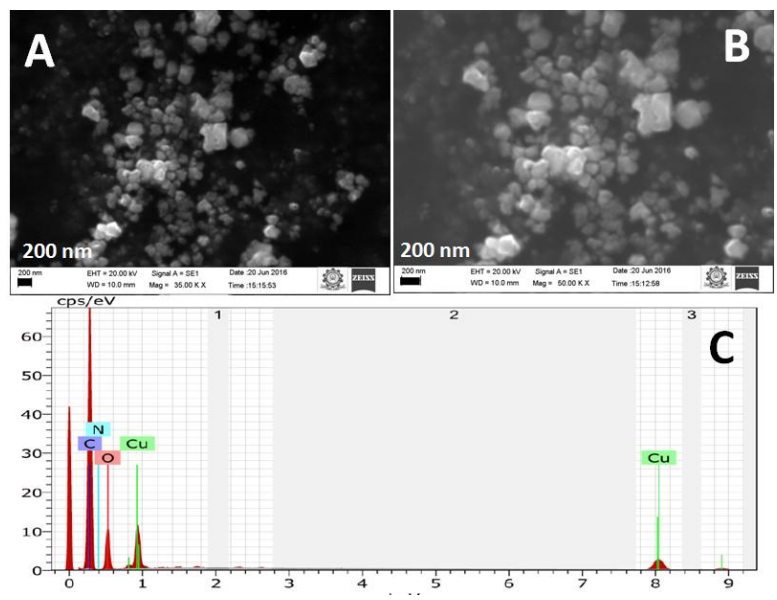

Fig. 2. SEM-EDX images of copper with alanine as capping agent

acids [19]. To explore in this direction, we checked it with alanine as capping agent.

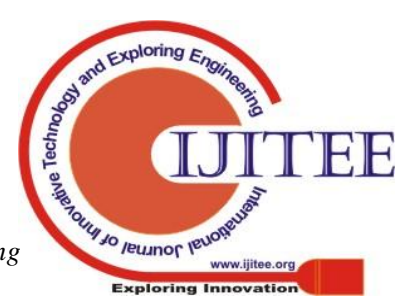


Thus, we have examined the alanine, which is having only a methyl group and expected to produce different shape of nanoparticles. For that purpose, copper sulfate $(5 \mathrm{~g})$ and $1 \mathrm{~g}$ $\mathrm{mL}$ of alanine were dissolved thoroughly in $100 \mathrm{~mL}$ water and performed the electrolytic deposition for $3 \mathrm{~h}$ duration. At the end of the reaction, the product obtained was centrifuged and washed with water and acetone to obtain the copper nanoparticles capped with alanine.

As shown in fig.2. the nanoparticles appears with variable dimensions and shapes, which is very similar to the nanoparticles synthesized without any capping agent under the electrolytic synthesis of copper nanoparticles (unpublished work) However the particle size distribution of these particles are falls between $200-800 \mathrm{~nm}$. However, when the copper nanoparticles were prepared with The EDX analysis also clearly indicates the presence of amino acid as the capping agent (Fig. 2C). The presence of carbon and nitrogen support the presence of amino acid and the presence of copper peaks at indicates the presence of copper as core material. Unlike the glutamic acid, alanine produced irregular shaped nanoparticles. As reported by Wei-Shi Li et. al. alanine with $\mathrm{Cu}\left(\mathrm{NO}_{3}\right)_{2}$ produced nanowire and nanoparticles together, when hydrazine was used as reducing agent [19]. Thus, both chemical reduction method and electrolytic reduction method produced a similar morphological structure, with little variation among them.

\section{CONCLUSION}

In conclusion, here we have reported the electrolytic synthesis of amino acids capped copper nanoparticles using alanine and glutamic acid as a representative of amino acids. There are many structural variations when the amino acid was changed from alanine to glutamic acid. On the other hand, reported chemical reduction method also produced a similar morphological structure with a little variation, although the synthetic strategies of these methods are very different. We are exploring the other amino acids as capping agent and expecting many interesting morphologies with them.

\section{ACKNOWLEDGMENT}

N. S thanks to the KARE for providing the instrumentation support to carry out the research. R. P thanks to KARE for offering University $\mathrm{PhD}$ fellowship. K. K. thanks to the KARE for offering the university fellowship..

\section{REFERENCES}

1. Y. Xiao, F. Patolsky, E. Katz, J.F. Hainfeld and I. Willner, "Plugging into Enzymes": Nanowiring of Redox Enzymes by a Gold Nanoparticle" Science vol. 299, March 2003, pp 1877-1881,

2. R. Paull, J. Wolfe, P. Hebert, and M. Sinkula, "Investing in nanotechnology", Nature Biotechnology, vol. 21, October 2003, pp 1134-1147.

3. E. Katz, I. Willner, "Integrated Nanoparticle-Biomolecule Hybrid Systems: Synthesis, Properties, and Applications" Angew. Chem. Int. Ed. Engl. Vol. 43 November. 2004, pp 6042-6108,

4. A. G. Tkachenko, H. Xie, Y. L. Liu, D. Coleman, J. Ryan, W. Glomm, M. K. Shipton, S. Franzen and D. L. Feldheim, "Cellular Trajectories of Peptide-Modified Gold Particle Complexes: Comparison of Nuclear Localization Signals and Peptide Transduction Domains" Bioconjugate Chem. Vol.15 pp. April 2004, 482-490,

5. D. Zhang, R. Wang, M. Wen, D. Weng, X. Cui, J. Sun, H. Li and Y. Lu, "Synthesis of Ultralong Copper Nanowires for High-Performance
Transparent Electrodes" J. Am. Chem. Soc., vol. 134, July 2012, .pp. $14283-14286$,

6. Z. Liu, J. Xu, D. Chen and G. Shen, "Flexible electronics based on inorganic nanowires" Chem. Soc. Rev., vol. 44, January 2015, 161 -192 ,

7. Y. Liu, Z. Liu, N. Lu, E. Preiss, S. Poyraz, M. J. Kim and X. Zhang, “ Facile synthesis of polypyrrole coated copper nanowires: a new concept to engineered core-shell structures" Chem. Commun., vol. 48 , January 2012, $2621-2623$,

8. S. Poyraz, Z. Liu, Y. Liu, N. Lu, M. J. Kim and X. Zhang, “One-step synthesis and characterization of poly(o-toluidine) nanofiber/metal nanoparticle composite networks as non-enzymatic glucose sensors" Sens. Actuators, B. , vol. 201, October 2014, $565-74$.

9. Y. Wei, S. Chen, B. Kowalczyk, S. Huda, T. P. Gray and B. A. Grzybowski, "Synthesis of Stable, Low-Dispersity Copper Nanoparticles and Nanorods and Their Antifungal and Catalytic Properties" J. Phys. Chem. C, vol. 114, August 2010, $15612-15616$

10. Z. Liu, Y. Liu, L. Zhang, S. Poyraz, N. Lu, M. Kim, J. Smith,Wang, Y. $\mathrm{Yu}$ and $\mathrm{X}$. Zhang, "Controlled synthesis of transition metal/conducting polymer nanocomposites" Nanotechnology, vol. 23, July 2012, pp. 335603 .

11. Y-Q Liu, M. Zhang, F-X. Wang and G-B. Pan, "Facile microwave-assisted synthesis of uniform single-crystal copper nanowires with excellent electrical conductivity" $R S C A d v$., vol. 2 , 11235-11237, Oct. 2012.

12. A. R. Rathmell, S. M. Bergin, Y. Hua, Z. Li and J. Benjamin, "The Growth Mechanism of Copper Nanowires and Their Properties in Flexible, Transparent Conducting Films" Wiley, Adv. Mater., vol. 22, August. 2010, 3558-3563,

13. Unpublished work: "Size Controllable Electrochemical Method of Preparation of Copper Nanoparticles with Various Capping Agents" IJRTE, submitted for publication.

14. R. Prakash, G. Usha, L. Piramuthu and N. Selvapalam, "Facile Detection of Cucurbit[7]uril by Rhodamine B-decorated Nanoparticles" Chem. Lett., vol. 46, September. 2017, 1300 - 1303,

15. R. Subapriya and S. Nagini, "Medicinal Properties of Neem Leaves: A Review" Current Medicinal Chemistry - Anti-Cancer Agents, Vol. pp. March. 2005, pp. 149-156,

16. J. Robbins "The excitation and inhibition of crustacean muscle by amino acids"J. Physiol., Vol. 148, October 1959, pp 39-50

17. M. T. Reetz, M. Winter, R. Breinbauer, T. Thurn-Albrecht, W. Vogel, "Size - Selective Electrochemical Preparation of Surfactant Stabilized Pd - , Ni - and Pt/Pd Colloids" Chem.s Eur. J., vol. 7, March. 2001, pp. 1084-1094,

18. S. S. Chang, C. W. Shih, C. D. Chen, W.-C. Lai, C. R. C. Wang, "The Shape Transition of Gold Nanorods”, Langmuir, vol. 15, March 1999, pp 701-709,

19. J-C. Yu, F-G. Zhao, W. Shao, C-W. Ge and W-S. Li, "Shape-controllable and versatile synthesis of copper nanocrystals with amino acids as capping agents", Nanoscale, vol. 7, April 2015, pp 8811-8818,

20. T. Theivasanthi and M. Alagar "Nano sized copper particles by electrolytic synthesis and characterizations", International Journal of the Physical Sciences vol. 6, August, 2011, pp. 3662-3671,

\section{AUTHORS PROFILE}

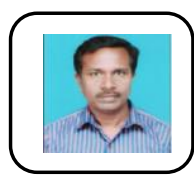

Dr. Narayanan Selvapalam received his M.S.and Ph.D degrees from Mysore University and IIT Delhi, respectively. $\mathrm{He}$ is presently working as Associate Professor at the Kalasalingam Academy of Research and Education (Kalasalingam University) His research interests include supramolecular chemistry, glycoluri based polymers, Chemistry of cucurbiturils and cyclodextrins, organic synthesis and sensors.

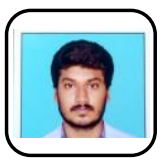

Ramesh Prakash born in Karur,Tamilnadu in 1991. He received his M.Phil degree from the BharathidasanUniversity, Trichy, in 2015 and obtained his MSc degree in 2014 at St. Joseph's College, Trichy. He joined Ph.D. in 2015 under the supervision of Dr. N. Selvapalam at Kalasalingam Academy of Research and Education inVirudhunagar district. He is awarded a direct-Senior Research Fellowship from CSIR in 2018 to till date. 


\section{Amino Acid as Capping Agent for Electrolytic Synthesis of Copper Nanoparticles}

His research interest is on the area of nanomaterials synthesis and supramolecular chemistry.

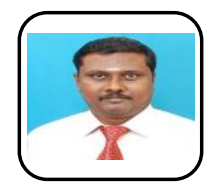

Dr. Sivasubramanian M. obtained his Bachelor's Degree in 1999 from Madurai Kamaraj University. Further he completed his Master's degree in Production Engineering from Anna University, India in 2005. He was awarded with Ph.D. degree in Faculty of Mechanical Engineering in the year 2015. During his research career he has published 14 International journals and participated and published many International conferences papers. He actively involved in inventing things related to automobile and mechanical engineering and as an outcome of this, he has registered 19 patents in INDIA. One of his inventions is eco-friendly hybrid electric car with self-electrical charging for which he received a fund of One lakh Rupees from Innovation and Entrepreneurship Development Centre, His research interest includes fluid dynamics, conjugate heat transfer, experimental heat transfer and flow separation using CFD techniques

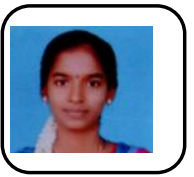

Karpagalakshmi karuppasamy was born in sivakasi, Tamilnadu in 1993. She received her M.. Sc. degree from the Madurai Kamaraj University, Madurai, in 2016 and obtained her B. Sc degree in 2014 from, Madurai Kamaraj University, Madurai. She has started her Ph. D. studies in 2016 under the supervision of Dr. N. Selvapalam at kalasalingam academy of Research and Education, Krishnankoil, India. Her research interests are in the area of organic synthesis, nano-materials and supramolecular chemistry

Dr. Lakshminarayanan Piramuthu was born in Kizhapuliyur, Tenkasi, India, in 1979. He studied Chemistry at Sri Paramakalyani College, Alwarkurichi, India. He obtained his Ph.D. degree in the area of Development of Receptors for Recognition of Halides and Water Clusters: Further Functionalization of Receptors with Fluorophoric Units from Indian Association for the Cultivation of Science IACS, Kolkata under the direction of Professor Pradyut Ghosh. His basic focus is, to study the biologically relevant anion recognition and sensing of the synthetic receptors, he has also contributed to other areas such as crystal engineering and organic synthesis. 